\title{
A Comparative Clinical Study between Concentrated Growth Factor and Low-Level Laser Therapy in the Management of Dry Socket
}

\author{
Aqsa Kamal ${ }^{1,2}$ Basheer Salman ${ }^{1}$ Noor Hayatie Abdul Razak ${ }^{2} \quad$ AB Rani Samsudin ${ }^{1, \odot}$ \\ ${ }^{1}$ Department of Oral and Craniofacial Health Sciences, College of \\ Dental Medicine, University of Sharjah, Sharjah, UAE \\ 2School of Dental Sciences, Universiti Sains Malaysia, Kelantan, \\ Malaysia \\ Address for correspondence AB Rani Samsudin, FDSRCS \\ (England), College of Dental Medicine, University of Sharjah, \\ University City Road - Sharjah 27272, UAE \\ (e-mail: drabrani@sharjah.ac.ae).
}

Eur J Dent:2020;14:613-620

\begin{abstract}
Objective A dry socket is a well-recognized complication of wound healing following tooth extraction. Its etiology is poorly understood and commonly occur among healthy patients. As such, management strategies for dry socket has always been empirical rather than scientific with varying outcome. The aim of this study is to investigate the efficacy of concentrated growth factor (CGF) and low-level laser therapy (LLLT) and compared them to the conventional treatment in the management of dry socket.

Materials and Methods Sixty patients with one dry socket each, at University Dental Hospital Sharjah, were divided into three treatment groups based on their choice. In group I $(n=30)$, conventional treatment comprising of gentle socket curettage and saline irrigation was done. Group II $(n=15)$ dry sockets were treated with CGF and group III $(n=15)$ sockets were lased with LLLT. All dry socket patients were seen at day 0 for treatment and subsequently followed-up at 4, 7, 14, and 21 days. Pain score, perisocket inflammation, perisocket tenderness, and amount of granulation tissue formation were noted.
\end{abstract}

Keywords

- dry socket

- granulation tissue

- low-level laser therapy

- concentrated growth factor

Statistical Analysis Data were analyzed as mean values for each treatment group. Comparisons were made for statistical analysis within the group and among the three groups to rank the efficacy of treatment using one-way analysis of variance (ANOVA). Statistically significant difference is kept at $p<0.05$.

Results Conventional treatment group I took more than 7 days to match the healing phase of group II CGF treated socket and group III LLLT irradiated socket $(p=0.001)$. When healing rate between CGF and LLLT are compared, LLLT group III showed a delay of 4 days compared with CGF in granulation tissue formation and pain control.

Conclusion CGF treated socket was superior to LLLT in its ability to generate $75 \%$ granulation tissue and eliminate pain symptom by day $7(p=0.001)$.

\section{Introduction}

A dry socket is a very common post-tooth-extraction complication, ${ }^{1}$ in which the socket is devoid of blood clot leaving bare bone. ${ }^{2}$ Management of dry socket has always been empirical rather than scientific. Different treatment options have been applied by practitioners, such as intrasocket placement of vitamin-C dressings, ${ }^{3}$ to take advantage of its antioxidant effects, introducing hyaluronic acid ${ }^{4}$ as a wound dressing, honey, ${ }^{5}$ and turmeric ${ }^{6}$ for its regenerative growth promoter capacity, and zinc oxide eugenol or pain relief dressing that uses butamben or iodoform for an antiseptic effect, eugenol, or an analgesic and antiseptic effect, and a biocompatible fibrous filler material, such as penghawar 
djambi, ${ }^{7}$ while topical rifampicin ${ }^{8}$ has been used for its antimicrobial property. Physiological saline ${ }^{8}$ and chlorhexidine has always been universally used for dry socket irrigation. All these methods are advocated for symptom relieve and protection of the compromised wound, but they do not precisely address the key issues in wound breakdown and efforts in regenerative therapy.

The current conventional method of dry socket treatment comprises of gentle curettage of the socket followed by saline irrigation and insertion of a pain relieve dressing, such as alvogyl which gives a soothing effect. The socket is then allowed to heal by natural process.

The etiology of dry socket and its treatment options are still debated. To understand dry socket, which is a delayed wound healing phenomenon, scientists should understand the factors involved in regulating the mechanisms of wound healing, to form a regenerative medicine approach to treating dry socket lesions. Current regenerative wound-healing technologies used intraorally in dentistry include platelet-rich plasma (PRP), ${ }^{9}$ concentrated growth factor (CGF), ${ }^{10,11}$ low-intensity pulsed ultrasound therapy (LIPUS) ${ }^{12}$ and low-level laser therapy (LLLT). ${ }^{13}$ These recently developed treatment options have shown effectiveness in general surgery and are now applied to intraoral wound healing strategies. These treatments are designed to enhance the natural regenerative abilities of cells at the molecular level.

CGF was first prepared by Corigliano in $2010 .{ }^{14}$ It is the newer third generation of autologous plasma which is extracted from one's blood by centrifugation..$^{15}$ It contains growth factors that act as the driver for tissue regeneration. ${ }^{16}$

LLLT was discovered by Endre Mester based on his observation of hair growth in mice following the application of laser light. ${ }^{17}$ It is basically a photochemical effect causing cellular stimulation on the skin. ${ }^{18}$ Such photostimulatory effect promotes fibroblast proliferation, ${ }^{18,19}$ stimulation of platelet-derived growth factor (PDGF), ${ }^{20}$ bone regeneration, ${ }^{18}$ and collagen synthesis ${ }^{20}$ with minimal thermal damage. ${ }^{20}$

Both concentrate growth factor processing kits and LLLT are currently made available in dental and oral surgery practices. The aim of this clinical study is to compare the efficacy of CGF and LLLT in the treatment of dry socket, and compare them with the conventional treatment technique of socket curettage and irrigation, followed by medicament application and the wait for the body to heal the lesion in a natural, unassisted way.

\section{Materials and Methods}

This study was conducted from August till December 2019 at University Dental Hospital Sharjah (UDHS), United Arab Emirates. Human Ethics, approval was obtained from the Research Ethics Committee, University of Sharjah, REC-1702-14-01-S, dated October 24, 2017.

Patients who were diagnosed with alveolar osteitis were referred to the oral surgery department. All healthy patients aged between 18 and 60 years, who had undergone nonsurgical tooth extraction, and diagnosed with alveolar osteitis were included in the study. All patients were given information regarding their dry socket condition and informed consent was obtained when they agree to take part in the study. They were given three treatment options and were then divided into three groups based on their treatment choice. Group-I patients were given conventional treatment while group-II patients received CGF and group-III patients had LLLT delivered to their dry sockets. A periapical radiograph of the socket was done for all groups before initiating treatment to exclude the presence of retained apices, bony fragments, and fracture of the alveolus.

In group-I, the dry socket was curetted and irrigated with saline under local anesthesia. A new bleeding socket was created following curettage and gentle saline irrigation help debride the necrotic debris. In group II, the same clinical procedure was repeated as for group I and PRP was prepared by obtaining $9 \mathrm{~mL}$ of the patient's blood into a vacuum blood collection tube. Blood centrifugation process was performed at the chairside using Medifuge centrifuge machine Silfradent, Italy, following a cycle duration of 5 minutes at 1,000 revolutions. The processing time is approximately 12 minutes, and it finally produced a thick yellowish color-like gel layer known as CGF. This CGF gel was directly delivered into the socket using a surgical tweezer. ${ }^{21-23}$

In group III, following necessary laser safety protection protocol, the socket was similarly curetted and irrigated under local anesthesia and the site was lased with LLLT. The irradiation was done at a setting of $200 \mathrm{~mW}, 6 \mathrm{~J}$, continuous wave mode using R02 tip-less handpiece (FotonaEr: YAG, Europe); on the buccal, lingual and the middle surface of the socket for 30 seconds from a delivery distance of $1 \mathrm{~cm} .{ }^{19}$

Patients in all groups were instructed to bite on a piece of sterile gauge to achieve hemostasis. No dressing, such as alvogyl or topical antibiotic, was placed in both groups and no systemic antibiotic was prescribed.

The day of presentation with a dry socket presentation was recorded as "day 0" and the patients were followed up at days 4 and 7 . At each clinical session, pain score was recorded using a visual analogue pain scale from 1 to 10.Clinical assessment also includes scoring perisocket inflammation and perisocket tenderness (- Table1). Quantification of

Table 1 Perisocket inflammation and perisocket tenderness clinical scoring system

\begin{tabular}{|l|l|}
\hline Perisocket inflammation & Sore \\
\hline Normal pink perisocket gingiva & 0 \\
\hline Mild redness at perisocket gingiva & 1 \\
\hline $\begin{array}{l}\text { Moderate redness with increase vascularity } \\
\text { at perisocket gingiva }\end{array}$ & 2 \\
\hline $\begin{array}{l}\text { Severe redness with increase vascularity at } \\
\text { perisocket gingiva extending to vestibule }\end{array}$ & 3 \\
\hline Perisocket tenderness & Score \\
\hline No perisocket tenderness on palpation & 0 \\
\hline Perisocket tenderness on palpation & 1 \\
\hline Perisocket tenderness on slight touch & 2 \\
\hline $\begin{array}{l}\text { Perisocket tenderness on slight touch } \\
\text { extending to vestibule and cheek }\end{array}$ & 3 \\
\hline
\end{tabular}


clinically evident granulation tissue (GT) formation within

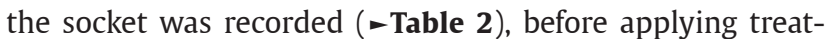
ment on day 0 , and following treatment application on days 4 and 7. A completely barren dry socket without GT was recorded as (nil). The formation of GT in one quarter or less of the socket was recorded as (+), while formation of GT in half of the socket was recorded as (++), three quarters were

Table 2 Scoring system employed for granulation tissue formation in the dry socket

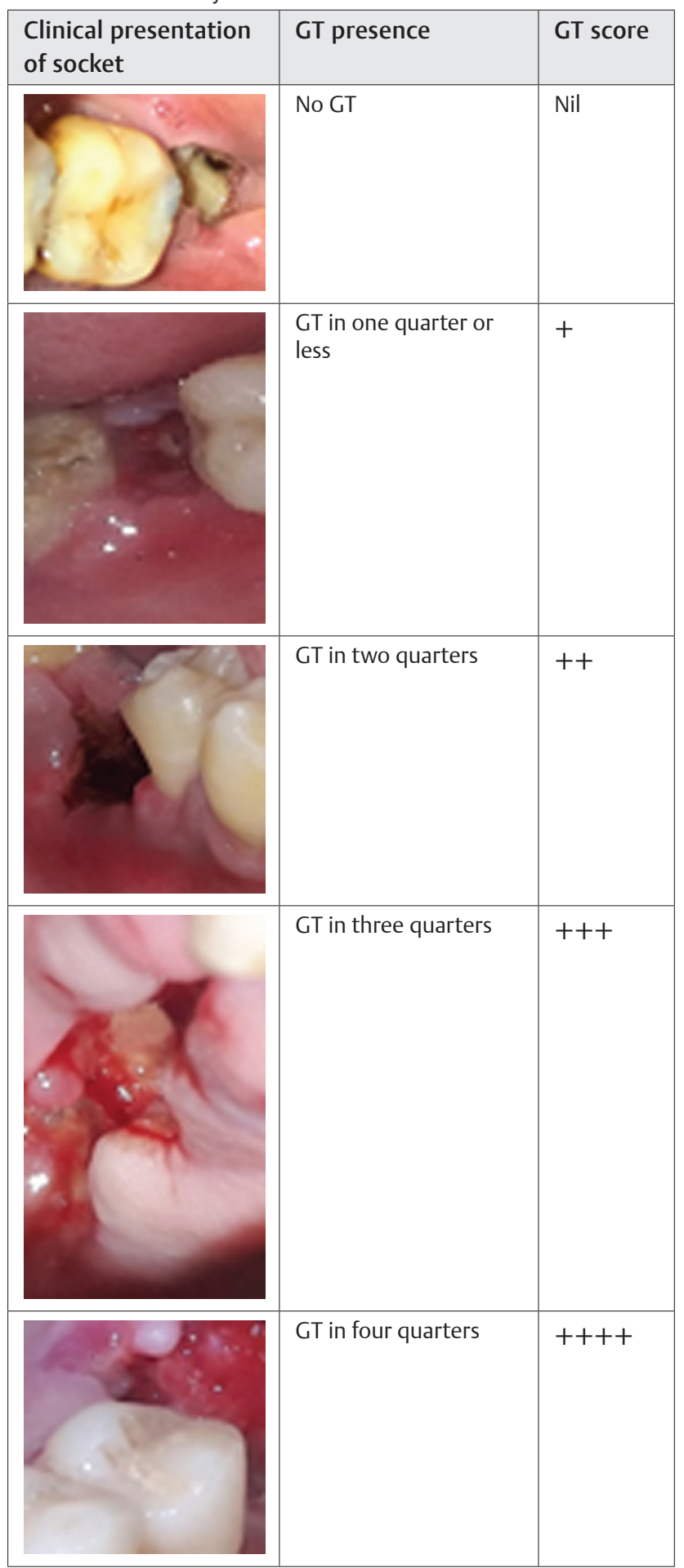

Abbreviation: GT, granulation tissue. recorded as $(+++)$, and the complete coverage of the socket surface with GT $(++++)$.

Continued follow-up of patients in all groups was done through phone calls on days 14 and 21 and their pain symptoms were notified by a "Yes" for pain persistence and a "No" when pain has subsided completely. A decision to return to clinic was made if the clinician feel that the healing and recovery was not satisfactory.

\section{Results}

A total of 60 patients with 60 dry sockets were included in this study, 38 male and 22 females (-Table $\mathbf{3}$ ). In the conventional group I, the pain score was 7 to 10 on the day of presentation (day 0 ) and the pain score reduced to 4 to 6 on day 4 and by day 7, it reduced to 2 to 4 following treatment. The pain score in CGF treated group II was noted to be 7 to 10 on day 0 , which reduced to 0 to 2 on day 4 and reduced to 0 to 1 on day 7 . Whereas the pain score in LLLT treated group III was 7 to 10 on day 0 ; reduced to 1 to 2 on day 4 and further reduced to 0 to 1 on day 7 ( - Table 3 ). The GT in group I appeared abundantly only on day 7 , whereas in in groups II and III, the patients who received CGF and LLLT showed richer and earlier GT formation by day 4 ( - Table 3 ).

The results were compared statistically for mean pain score, perisocket inflammation score, perisocket tenderness score, GT formation for all three groups(-Table 4 ), and for continuity of pain on days 14 and 21 (-Table 5 ).

\section{Discussion}

The incidence of dry socket in University Dental Hospital Sharjah is around 3\% compared with the incidence of dry socket worldwide which has been reported as ranging from 1 to $4 \%{ }^{19}$ following routine dental extractions; and the incidence is 10 times greater for lower teeth compared with the upper teeth, and may even reach $45 \%$ for mandibular third molar removal. ${ }^{24}$

Dental practitioners very often underestimate the degree of pain severity among dry socket sufferers and occasionally not much attention was given to the sufferers. Although the perisocket inflammation occasionally spread to the buccal vestibule and even toward the cheek in 13 cases, there seems to be no rise in body temperature. This phenomenon confirmed that the classical dry socket is a local pathology, involving the maxillary or mandibular alveolar process, without systemic upset. ${ }^{2}$

Thirty patients in group I received conventional treatment while 15 patients in group II were treated with CGF and another 15 patients in group III had their dry socket lased with LLLT.

In group I $(n=30)$, the perisocket inflammation seems to subside very slowly, beginning on day 4 with moderate redness and further improve to mild redness on day 7 . This observation is in tandem with the perisocket tenderness score which still show severe tenderness beyond day 7 . GT formation begin to fill in the dry socket bed 2 days after 
616 A Comparative Clinical Study in the Management of Dry Socket Kamal et al.

Table 3 Treatment response from the three options of dry socket treatment

\begin{tabular}{|c|c|c|c|c|c|c|c|c|c|c|c|c|c|c|c|c|c|}
\hline \multirow{2}{*}{$\begin{array}{l}\text { Patient } \\
\text { no. }\end{array}$} & \multirow[t]{2}{*}{ Age (y) } & \multirow[t]{2}{*}{ Gender } & \multirow{2}{*}{$\begin{array}{l}\text { Treatment } \\
\text { option }\end{array}$} & \multicolumn{4}{|c|}{ Day 0} & \multicolumn{4}{|c|}{ Day 4} & \multicolumn{4}{|c|}{ Day 7} & \multirow{2}{*}{$\begin{array}{l}\text { Day } \\
14 \\
\text { Pain }\end{array}$} & \multirow{2}{*}{$\begin{array}{l}\text { Day } \\
21 \\
\text { Pain }\end{array}$} \\
\hline & & & & Pain & PSI & PST & GT & Pain & PSI & PST & GT & Pain & PSI & PST & GT & & \\
\hline 1 & 53 & Female & CGF & 7 & 2 & 3 & $\mathrm{Nil}$ & 0 & 0 & 1 & + & 0 & 0 & 0 & ++ & No & No \\
\hline 2 & 39 & Female & CGF & 8 & 2 & 3 & $\mathrm{Nil}$ & 0 & 1 & 0 & ++ & 0 & 0 & 0 & +++ & No & No \\
\hline 3 & 28 & Male & Control & 10 & 3 & 3 & Nil & 6 & 2 & 2 & $\mathrm{Nil}$ & 3 & 2 & 1 & + & No & No \\
\hline 4 & 35 & Male & Control & 9 & 2 & 3 & Nil & 5 & 2 & 2 & + & 5 & 2 & 2 & + & Yes & Yes \\
\hline 5 & 38 & Male & Control & 8 & 2 & 2 & $\mathrm{Nil}$ & 6 & 2 & 2 & $\mathrm{Nil}$ & 3 & 1 & 2 & + & No & No \\
\hline 6 & 33 & Male & CGF & 9 & 2 & 2 & Nil & 1 & 0 & 0 & ++ & 0 & 0 & 0 & +++ & No & No \\
\hline 7 & 38 & Male & CGF & 8 & 3 & 3 & $\mathrm{Nil}$ & 0 & 0 & 0 & ++ & 0 & 0 & 0 & ++ & No & No \\
\hline 8 & 29 & Male & CGF & 9 & 2 & 3 & Nil & 0 & 1 & 1 & + & 0 & 0 & 0 & +++ & No & No \\
\hline 9 & 40 & Female & Control & 10 & 2 & 2 & Nil & 5 & 2 & 2 & Nil & 3 & 2 & 1 & + & No & No \\
\hline 10 & 49 & Female & Control & 8 & 2 & 3 & Nil & 4 & 2 & 3 & Nil & 3 & 1 & 1 & + & No & No \\
\hline 11 & 42 & Male & Control & 9 & 2 & 3 & Nil & 5 & 2 & 3 & Nil & 0 & 2 & 2 & + & No & No \\
\hline 12 & 40 & Female & CGF & 9 & 2 & 3 & $\mathrm{Nil}$ & 1 & 0 & 0 & ++ & 0 & 0 & 0 & +++ & No & No \\
\hline 13 & 38 & Female & CGF & 7 & 2 & 2 & $\mathrm{Nil}$ & 0 & 1 & 1 & + & 0 & 0 & 0 & +++ & No & No \\
\hline 14 & 40 & Male & CGF & 7 & 3 & 2 & Nil & 0 & 1 & 0 & ++ & 0 & 0 & 0 & ++ & No & No \\
\hline 15 & 35 & Male & Control & 8 & 2 & 2 & Nil & 4 & 2 & 2 & Nil & 0 & 1 & 1 & + & No & No \\
\hline 16 & 32 & Female & Control & 8 & 3 & 3 & Nil & 5 & 2 & 3 & Nil & 4 & 2 & 2 & + & Yes & Yes \\
\hline 17 & 49 & Male & CGF & 8 & 2 & 3 & $\mathrm{Nil}$ & 1 & 0 & 0 & ++ & 0 & 0 & 0 & ++ & No & No \\
\hline 18 & 31 & Male & CGF & 8 & 2 & 2 & $\mathrm{Nil}$ & 0 & 0 & 0 & ++ & 0 & 0 & 0 & +++ & No & No \\
\hline 19 & 42 & Female & Control & 7 & 2 & 2 & Nil & 3 & 2 & 3 & $\mathrm{Nil}$ & 5 & 2 & 2 & + & Yes & Yes \\
\hline 20 & 36 & Male & Control & 8 & 2 & 3 & Nil & 5 & 2 & 3 & Nil & 3 & 1 & 2 & + & No & No \\
\hline 21 & 27 & Male & Control & 10 & 3 & 3 & Nil & 6 & 3 & 2 & Nil & 4 & 2 & 1 & + & Yes & No \\
\hline 22 & 42 & Female & Control & 8 & 2 & 3 & Nil & 5 & 2 & 2 & + & 3 & 2 & 2 & + & No & No \\
\hline 23 & 36 & Male & Control & 9 & 2 & 3 & $\mathrm{Nil}$ & 6 & 2 & 2 & $\mathrm{Nil}$ & 4 & 2 & 2 & + & Yes & Yes \\
\hline 24 & 51 & Male & Control & 8 & 2 & 2 & $\mathrm{Nil}$ & 4 & 2 & 2 & $\mathrm{Nil}$ & 3 & 2 & 2 & + & No & No \\
\hline \multirow[t]{2}{*}{ No. } & $\begin{array}{l}\text { Age } \\
\text { (y) }\end{array}$ & Gender & Treatment & \multicolumn{4}{|c|}{ Day 0} & \multicolumn{4}{|c|}{ Day 4} & \multicolumn{4}{|c|}{ Day 7} & $\begin{array}{l}\text { Day } \\
14\end{array}$ & $\begin{array}{l}\text { Day } \\
21\end{array}$ \\
\hline & & & & Pain & PSI & PST & GT & Pain & PSI & PST & GT & Pain & PSI & PST & GT & Pain & Pain \\
\hline 25 & 35 & Female & Control & 10 & 2 & 3 & Nil & 6 & 2 & 3 & + & 3 & 1 & 2 & + & No & No \\
\hline 26 & 49 & Male & Control & 9 & 3 & 2 & Nil & 7 & 3 & 2 & Nil & 2 & 1 & 1 & + & No & No \\
\hline 27 & 60 & Male & Control & 9 & 2 & 3 & Nil & 6 & 2 & 3 & Nil & 3 & 1 & 2 & + & No & No \\
\hline 28 & 40 & Female & Control & 8 & 2 & 2 & $\mathrm{Nil}$ & 5 & 2 & 2 & $\mathrm{Nil}$ & 3 & 2 & 2 & + & Yes & No \\
\hline 29 & 47 & Male & Control & 8 & 2 & 2 & Nil & 7 & 2 & 2 & $\mathrm{Nil}$ & 2 & 2 & 2 & + & No & No \\
\hline 30 & 40 & Female & Control & 7 & 3 & 3 & Nil & 7 & 3 & 2 & Nil & 4 & 2 & 2 & + & Yes & Yes \\
\hline 31 & 57 & Male & Control & 10 & 2 & 2 & Nil & 6 & 2 & 2 & + & 4 & 1 & 1 & ++ & No & No \\
\hline 32 & 36 & Female & Control & 8 & 2 & 2 & Nil & 6 & 2 & 2 & Nil & 4 & 1 & 2 & + & Yes & No \\
\hline 33 & 23 & Male & Control & 9 & 2 & 3 & $\mathrm{Nil}$ & 6 & 2 & 2 & + & 4 & 2 & 2 & ++ & No & No \\
\hline 34 & 23 & Male & Control & 8 & 3 & 3 & Nil & 5 & 3 & 2 & Nil & 4 & 2 & 2 & + & Yes & Yes \\
\hline 35 & 27 & Male & Control & 8 & 2 & 3 & $\mathrm{Nil}$ & 4 & 2 & 2 & Nil & 3 & 1 & 1 & ++ & No & No \\
\hline 36 & 23 & Male & Control & 8 & 2 & 3 & Nil & 4 & 2 & 2 & Nil & 2 & 1 & 2 & + & No & No \\
\hline 37 & 40 & Female & Control & 10 & 2 & 2 & Nil & 4 & 2 & 2 & + & 2 & 2 & 1 & ++ & No & No \\
\hline 38 & 38 & Male & Control & 10 & 2 & 2 & Nil & 5 & 2 & 2 & + & 3 & 1 & 1 & ++ & No & No \\
\hline 39 & 30 & Male & Control & 9 & 3 & 3 & Nil & 4 & 3 & 2 & Nil & 3 & 3 & 2 & + & Yes & Yes \\
\hline 40 & 30 & Female & Control & 9 & 2 & 3 & $\mathrm{Nil}$ & 4 & 2 & 2 & $\mathrm{Nil}$ & 2 & 2 & 2 & + & No & No \\
\hline 41 & 35 & Male & LLLT & 7 & 3 & 2 & Nil & 1 & 1 & 1 & + & 0 & 0 & 0 & ++ & No & No \\
\hline 42 & 38 & Male & LLLT & 8 & 2 & 2 & Nil & 1 & 1 & 0 & + & 0 & 0 & 0 & ++ & No & No \\
\hline
\end{tabular}


Table 3 (Continued)

\begin{tabular}{|c|c|c|c|c|c|c|c|c|c|c|c|c|c|c|c|c|c|}
\hline \multirow{2}{*}{$\begin{array}{l}\text { Patient } \\
\text { no. }\end{array}$} & \multirow[t]{2}{*}{ Age (y) } & \multirow[t]{2}{*}{ Gender } & \multirow{2}{*}{$\begin{array}{l}\text { Treatment } \\
\text { option }\end{array}$} & \multicolumn{4}{|c|}{ Day 0} & \multicolumn{4}{|c|}{ Day 4} & \multicolumn{4}{|c|}{ Day 7} & \multirow{2}{*}{\begin{tabular}{|l|} 
Day \\
14 \\
Pain \\
\end{tabular}} & \multirow{2}{*}{\begin{tabular}{|l|} 
Day \\
21 \\
Pain \\
\end{tabular}} \\
\hline & & & & Pain & PSI & PST & GT & Pain & PSI & PST & GT & Pain & PSI & PST & GT & & \\
\hline 43 & 39 & Female & LLLT & 9 & 3 & 3 & Nil & 1 & 0 & 0 & ++ & 0 & 0 & 0 & +++ & No & No \\
\hline 44 & 42 & Female & LLLT & 8 & 2 & 3 & Nil & 2 & 0 & 1 & + & 1 & 1 & 1 & ++ & No & No \\
\hline 45 & 28 & Male & LLLT & 10 & 2 & 2 & Nil & 1 & 2 & 0 & + & 0 & 0 & 0 & ++ & No & No \\
\hline 46 & 30 & Male & LLLT & 8 & 3 & 3 & Nil & 1 & 2 & 1 & + & 0 & 0 & 0 & ++ & No & No \\
\hline 47 & 45 & Male & LLLT & 7 & 2 & 3 & Nil & 1 & 0 & 0 & ++ & 0 & 0 & 0 & +++ & No & No \\
\hline 48 & 42 & Female & LLLT & 8 & 2 & 3 & Nil & 1 & 0 & 0 & ++ & 0 & 0 & 0 & +++ & No & No \\
\hline 49 & 33 & Male & LLLT & 10 & 2 & 3 & Nil & 1 & 1 & 1 & + & 0 & 0 & 0 & ++ & No & No \\
\hline 50 & 40 & Male & LLLT & 9 & 2 & 2 & Nil & 1 & 0 & 0 & + & 0 & 0 & 0 & ++ & No & No \\
\hline 51 & 32 & Female & LLLT & 7 & 2 & 3 & $\mathrm{Nil}$ & 1 & 0 & 0 & + & 0 & 0 & 0 & +++ & No & No \\
\hline 52 & 43 & Female & LLLT & 9 & 2 & 3 & Nil & 1 & 0 & 1 & + & 0 & 0 & 0 & ++ & No & No \\
\hline 53 & 31 & Male & LLLT & 8 & 2 & 3 & Nil & 2 & 0 & 0 & + & 1 & 1 & 1 & ++ & No & No \\
\hline 54 & 39 & Male & LLLT & 8 & 2 & 2 & Nil & 1 & 0 & 0 & ++ & 0 & 0 & 0 & ++ & No & No \\
\hline \multirow[t]{2}{*}{ No. } & $\begin{array}{l}\text { Age } \\
(y)\end{array}$ & Gender & Treatment & \multicolumn{4}{|c|}{ Day 0} & \multicolumn{4}{|c|}{ Day 4} & \multicolumn{4}{|c|}{ Day 7} & $\begin{array}{l}\text { Day } \\
14\end{array}$ & $\begin{array}{l}\text { Day } \\
21\end{array}$ \\
\hline & & & & Pain & PSI & PST & GT & Pain & PSI & PST & GT & Pain & PSI & PST & GT & Pain & Pain \\
\hline 55 & 29 & Male & LLLT & 10 & 2 & 2 & Nil & 1 & 0 & 0 & + & 0 & 0 & 0 & +++ & No & No \\
\hline 56 & 33 & Male & CGF & 10 & 2 & 2 & Nil & 0 & 0 & 0 & + & 0 & 0 & 0 & ++++ & No & No \\
\hline 57 & 32 & Female & CGF & 9 & 2 & 3 & Nil & 0 & 0 & 0 & ++ & 0 & 0 & 0 & ++++ & No & No \\
\hline 58 & 53 & Male & CGF & 9 & 3 & 3 & Nil & 0 & 0 & 0 & ++ & 0 & 0 & 0 & +++ & No & No \\
\hline 59 & 50 & Male & CGF & 10 & 2 & 3 & Nil & 1 & 0 & 0 & + & 0 & 0 & 0 & ++++ & No & No \\
\hline 60 & 50 & Female & CGF & 10 & 2 & 2 & Nil & 0 & 0 & 0 & ++ & 0 & 0 & 0 & ++++ & No & No \\
\hline
\end{tabular}

Abbreviations: Control, conventional treatment; CGF, concentrate growth factor; GT, granulation tissue; LLLT, low level laser therapy; PSI, perisocket inflammation; PST, perisocket tenderness.

Note: "+" denotes quantity of GT in socket.

Table 4 Mean clinical score for perisocket inflammation, perisocket tenderness, VAS pain score and granulation tissue score for all three treatment groups

\begin{tabular}{|c|c|c|c|c|c|c|c|c|c|c|c|c|c|}
\hline \multirow[b]{2}{*}{ Day } & \multirow[b]{2}{*}{ Group } & \multicolumn{3}{|c|}{$\begin{array}{c}\text { Perisocket } \\
\text { inflammation score }\end{array}$} & \multicolumn{3}{|c|}{$\begin{array}{c}\text { Perisocket } \\
\text { tenderness score }\end{array}$} & \multicolumn{3}{|c|}{ Pain score } & \multicolumn{3}{|c|}{$\begin{array}{l}\text { Granulation } \\
\text { tissue score }\end{array}$} \\
\hline & & Mean & SD & $p$-Value & Mean & SD & $p$-Value & Mean & SD & $p$-Value & Mean & SD & $p$-Value \\
\hline \multirow[t]{3}{*}{ Day 0} & Group I & 2.23 & \pm 0.43 & \multirow[t]{3}{*}{0.954} & 2.63 & \pm 0.49 & \multirow[t]{3}{*}{0.967} & 8.67 & \pm 0.92 & \multirow[t]{3}{*}{0.690} & 0.01 & \pm 0.00 & - \\
\hline & Group II & 2.20 & \pm 0.41 & & 2.60 & \pm 0.50 & & 8.53 & \pm 1.06 & & 0.01 & \pm 0.00 & \\
\hline & Group III & 2.20 & \pm 0.41 & & 2.60 & \pm 0.50 & & 8.40 & \pm 1.05 & & 0.01 & \pm 0.00 & \\
\hline \multirow[t]{3}{*}{ Day 4} & Group I & 2.17 & \pm 0.37 & \multirow[t]{3}{*}{0.001} & 2.20 & \pm 0.40 & \multirow[t]{3}{*}{0.001} & 5.17 & \pm 1.05 & \multirow[t]{3}{*}{0.001} & 0.23 & \pm 0.43 & 0.001 \\
\hline & Group II & 0.27 & \pm 0.45 & & 0.20 & \pm 0.41 & & 0.27 & \pm 0.45 & & 1.67 & \pm 0.48 & \\
\hline & Group III & 0.47 & \pm 0.74 & & 0.33 & \pm 0.48 & & 1.13 & \pm 0.35 & & 1.27 & \pm 0.45 & \\
\hline \multirow[t]{3}{*}{ Day 7} & Group I & 1.63 & \pm 0.55 & \multirow[t]{3}{*}{0.001} & 1.67 & \pm 0.47 & \multirow[t]{3}{*}{0.001} & 3.03 & \pm 1.15 & \multirow[t]{3}{*}{0.001} & 1.17 & \pm 0.37 & 0.001 \\
\hline & Group II & 0.01 & \pm 0.00 & & 0.01 & \pm 0.00 & & 0.01 & \pm 0.00 & & 3.00 & \pm 0.75 & \\
\hline & Group III & 0.13 & \pm 0.35 & & 0.13 & \pm 0.35 & & 0.13 & \pm 0.35 & & 2.33 & \pm 0.48 & \\
\hline
\end{tabular}

Abbreviations: SD, standard deviation; VAS, visual analogue scale.

treatment and none of the sockets out of 30 sockets had $75 \%$ GT by day 7 posttreatment. It seems that it needs at least $75 \%$ of socket to be filled with GT before the pain symptoms subside completely. Group I demonstrated the natural wound healing process that need around 10 days for an extraction wound socket to heal with complete epithelialization. In this study, socket curettage had created bleeding and clotting in a compromised tooth socket that failed the primary attempt to heal. Gentle socket curettage followed by saline irrigation helps to debride the necrotic hard and soft tissue that is unable to be eliminated by the natural physiological process. Since all the patients are healthy, there was no problem in their healing potential, although a delay was expected following establishment of the new clot. 
Table 5 Pain symptom scores (yes) on day 14 and 21 for all groups

\begin{tabular}{|l|l|l|l|l|}
\hline Day & Group & Mean & SD & \multirow{2}{*}{0.002} \\
\hline \multirow{3}{*}{ Day 14 } & Group I & 1.67 & \pm 0.47 & \\
\cline { 2 - 4 } & Group II & 2.00 & \pm 0.00 & \\
\cline { 2 - 4 } & Group III & 2.00 & \pm 0.00 & \multirow{2}{*}{0.018} \\
\cline { 2 - 4 } & Group I 1 & 1.77 & \pm 0.43 & \\
\cline { 2 - 4 } & Group II & 2.00 & \pm 0.00 & \\
\cline { 2 - 4 } & Group III & 2.00 & \pm 0.00 & \\
\hline
\end{tabular}

Abbreviation: SD, standard deviation.

In group II $(n=15)$, introduction of CGF into the socket is expected to support healing in the compromised healing socket. Following curettage and saline irrigation, the gel-like CGF was easily delivered into the socket and it tended to stick well, although sometimes there is a need for stabilization with sutures, particularly for maxillary sockets. All patients in group II were initially seen with a mean pain score of 8.53 and the pain symptoms surprisingly dropped to 0.27 by day 4. This is further supported by clinical observation whereby there was fast resolution of perisocket inflammation with subsidence of tenderness by day 4 in all sockets. GT began to fill in the socket quickly by day 4 and four sockets were completely covered by GT by day 7 . Tenderness around the inflamed socket subsided by day 4 as the GT invaded the socket and pain symptom decreases and subsequently the visual analogue scale (VAS) pain score was reduced to zero for all sockets by day 7 .

In group III $(n=15)$, the dry sockets with its new clot formed following curettage were lased with low-level laser over its entire buccal, occlusal and lingual surface. It was interesting to note that the mean perisocket inflammation was reduced to 0.47 on day 4 and perisocket tenderness reduced to 0.33 on day 4 . GT has filled in $75 \%$ of the socket by day 7. At day 7, all sockets, except for two, have healed completely, pain symptoms and tenderness have subsided and patients have resumed to normal diet.

The follow-up phone call on day 14 showed 15 sockets in group II receiving CGF had complete resolution of pain, as well as 15 sockets in LLLT-delivered group III but 10 sockets in conventionally treated group I are still symptomatic. At day 21 , seven sockets in conventionally treated group I was still having pain symptoms and were still on follow-up at the oral surgery clinic in University Dental Hospital Sharjah.

It has been a common observation that following adequate treatment, dry sockets took a few days longer to heal than uncomplicated healing sockets. ${ }^{25}$ The idea of supporting and promoting healing by addition of CGF arises from experiences in general surgical wound healing. Its scientific application in oral surgery provide a cocktail of growth factors that act together in the newly freshened dry socket and enhances the healing potential through its immune-modulation properties ${ }^{26}$ that are able to suppress inflammation, recruit, and proliferate the appropriate cells for regenerative capacity. Pain and tenderness are reduced enabling return of early oral functions.
LLLT was only recently introduced in dental surgery over the last two decades. Its earlier use in the orofacial region was geared toward esthetic medicine where low level laser light is able to penetrate skin and subsequently stimulate fibroblast, collagen synthesis, and hyaluronic acid production for facial rejuvenation. Oral wound healing mechanisms are supported through biostimulation at the cell and molecular level, enhancing growth factors activity that include platelet derived growth factor and insulin-like growth factor on fibroblast proliferation and collagen production. LLLT promotes proliferation and migration of human gingival fibroblast, as well as other cellular effects, and responses, such as protein production and growth factor expression. ${ }^{27-30}$

Treatment strategies for dry socket are difficult to identify because the etiology of dry socket is not well understood. This study suggests that the conventional treatment for dry socket that relies on the body's natural healing process, is less effective compared with treatments using regenerative molecular or light stimulation. CGF and LLLT have demonstrated its superiority in enhancing dry socket wound healing compared with the conventional technique with respect to reducing inflammation, producing GT, and relieving pain. Angiogenesis is an important phase in wound healing mechanism. CGF is a pack of several essential growth factors that include vascular endothelial growth factor (VEGF), responsible for angiogenesis and formation of new blood vessels. ${ }^{16}$

Autologous CGF is safe to use without immunological rejection. Its preparation technique is easily learned and the processing work for CGF production can be conducted at the chairside in the dental office or oral surgery suite at an affordable cost. However, there are infection risk involved during the processing stage and the procedure may be subjected to certain legal conditions in some countries. Furthermore, the extra CGF processing time needed may impose time constraint in a busy practice. LLLT on the other hand is much simpler to apply since it only involves delivering light energy using a special dental laser hand piece or laser fiber tip to the tooth socket. The power dose requirements and setting parameters are easily learned and the procedure is sterile and pain free unlike CGF where at least $9 \mathrm{~mL}$ of blood need to be withdrawn to produce the growth factor-rich gel. However, laser technology is costly and the need to adhere to Laser Protection Protocol may be an obstacle to provide this armamentarium in all surgical practice. Moreover, there is still a gap in the search for the ideal LLLT irradiation parameters 
for surgical procedures in oral surgery that is capable of promoting appropriate biostimulatory effects on cells involved in regenerative process. ${ }^{31}$ This discrepancy in parameter settings has led to diverse claims in clinical outcome following LLLT application in wound healing strategies.

Both CGF and LLLT help accelerate the synthesis of GT in dry socket. This study shows that pain symptom in the healing dry socket is inversely proportional to the amount of GT formation. GT is new reddish connective tissue and microscopic blood vessels that forms at the base of the dry socket during the healing process. It is the prime clinical predictor in assessing how well the body is coping with the injury. Sometimes, hypergranulation may occur with excess of GT formation as was seen in one patient from group II. On the other hand, development and presence of endogenous growth factor inhibitors at the CGF implantation site may interfere with binding of the growth factor to the corresponding growth factor receptors, impeding cell growth and possibly delaying GT formation in wound healing. ${ }^{32}$ These include epidermal growth factor receptor inhibitor (EGFR-I), PDGF-I, and VEGF-I. New exogenous growth factor delivery systems are now being developed to carry, deliver and control the spatiotemporal delivery of growth factors required for the effective and safe use of growth factors as regenerative treatments in clinical practice, and mitigate the effects of endogenous growth factor inhibitors. ${ }^{33}$

Comparison of healing rate among the three groups in this study showed that the conventional treatment group I took more than 7 days to match the healing phase of group-II CGFtreated socket and group-III LLLT-exposed socket $(p<0.05)$. When healing rate between CGF and LLLT are compared, LLLT group III showed a delay of 4 days compared with CGF in GT formation and pain control. CGF treated socket was superior to LLLT in its ability to generate $75 \%$ GT and eliminate pain symptom completely by day $7(p=0.001)$.

\section{Conclusion}

Occurrence of dry socket brought severe pain and misery to healthy patients following even simple tooth extraction. Conventional dry socket treatment employing gentle curettage and irrigation still produce a slow healing process. CGF and LLLT help accelerate the rate of GT formation and reduction of pain symptom. CGF is superior to LLLT in its capacity to generate GT and eliminate pain symptom within the first 7 days of treatment.

\section{Funding}

None.

\section{Conflict of Interest}

None declared.

\section{References}

1 Almutairi BM. Dry sockets-a systemic review. Advancements in Life Sciences 2019;7:48-57

2 Mamoun J. Dry socket etiology, diagnosis, and clinical treatment techniques. J Korean Assoc Oral Maxillofac Surg 2018;44(2):52-58
3 Halberstein RA, Abrahmsohn GM. Clinical management and control of alveolalgia ("dry socket") with vitamin C. Am J Dent 2003;16(3):152-154

4 Dubovina D, Mihailović B, Bukumirić Z, et al. The use of hyaluronic and aminocaproic acid in the treatment of alveolar osteitis. Vojnosanit Pregl 2016;73(11):1010-1015

5 Ansari A, Joshi S, Garad A, Mhatre B, Bagade S, Jain R. A study to evaluate the efficacy of honey in the management of dry socket. Contemp Clin Dent 2019;10(1):52-55

6 Lone PA, Ahmed SW, Prasad V, Ahmed B. Role of turmeric in management of alveolar osteitis (dry socket): a randomised clinical study. J Oral Biol Craniofac Res 2018;8(1): 44-47

7 Supe NB, Choudhary SH, Yamyar SM, Patil KS, Choudhary AK, Kadam VD. Efficacy of alvogyl (combination of iodoform + butylparaminobenzoate) and zinc oxide eugenol for dry socket. Ann Maxillofac Surg 2018;8(2):193-199

8 Çebi AT. Evaluation of the effects of intra-alveolar irrigation with clindamycin, rifampicin and sterile saline in alveolar osteitis treatment. J Stomatol Oral Maxillofac Surg 2020:2468-7855

9 Prataap N, Sunil PM, Sudeep CB, Ninan VS, Tom A, Arjun MR. Platelet-rich plasma and incidence of alveolar osteitis in highrisk patients undergoing extractions of mandibular molars: a case-control study. J Pharm Bioallied Sci 2017;9(suppl 1) : S173-S179

10 Xu Y, Qiu J, Sun Q et al. One-year results evaluating the effects of concentrated growth factors on the healing of intrabony defects treated with or without bone substitute in chronic periodontitis. Med Sci Monit 2019;25:4384-4389

11 Masuki H, Okudera T, Watanebe T, et al. Growth factor and pro-inflammatory cytokine contents in platelet-rich plasma (PRP), plasma rich in growth factors (PRGF), advanced platelet-rich fibrin (A-PRF), and concentrated growth factors (CGF) Int J Implant Dent 2016;2(1):19

12 Tanaka E, Kuroda S, Horiuchi S, Tabata A, El-Bialy T. Lowintensity pulsed ultrasound in dentofacial tissue engineering. Ann Biomed Eng 2015;43(4):871-886

13 Parihar AS, Pathak R. Effect of low level laser therapy (LLLT) on post extraction wound healing. Journal of Advanced Medical and Dental Sciences Research 2018;6:6-14

14 Corigliano M, Sacco L, Cipollina A, Crescentini F, Baldoni E. Concentrated Growth Factors (CGFs) in the restorative tissue techniques. J Dent Res 2010;89:4691

15 Malli Sureshbabu N, Selvarasu K, V JK, Nandakumar M, Selvam D. Concentrated growth factors as an ingenious biomaterial in regeneration of bony defects after periapical surgery: a report of two cases. Case Rep Dent 2019;2019:7046203

16 Jin R, Song G, Chai J, Gou X, Yuan G, Chen Z. Effects of concentrated growth factor on proliferation, migration, and differentiation of human dental pulp stem cells in vitro. J Tissue Eng 2018;9:2041731418817505

17 Chung H, Dai T, Sharma SK, Huang YY, Carroll JD, Hamblin MR. The nuts and bolts of low-level laser (light) therapy. Ann Biomed Eng 2012;40(2):516-533

18 Hamad SA, Naif JS, Abdullah MA. Effect of diode laser on healing of tooth extraction socket: an experimental study in rabbits. J Maxillofac Oral Surg 2016;15(3):308-314

19 Eshghpour M, Ahrari F, Najjarkar NT, Khajavi MA. Comparison of the effect of low level laser therapy with alvogyl on the management of alveolar osteitis. Med Oral Patol Oral Cir Bucal 2015;20(3):e386-e392

20 Kesler G, Shvero DK, Tov YS, Romanos G. Platelet derived growth factor secretion and bone healing after Er:YAG laser bone irradiation. J Oral Implantol 2011;37(Spec No) :195-204

21 Haraji A, Lassemi E, Motamedi MH, Alavi M, Adibnejad S. Effect of plasma rich in growth factors on alveolar osteitis. Natl J Maxillofac Surg 2012;3(1):38-41 
22 Rutkowski JL, Johnson DA, Radio NM, Fennell JW. Platelet rich plasma to facilitate wound healing following tooth extraction. J Oral Implantol 2010;36(1):11-23

23 Lubkowska A, Dolegowska B, Banfi G. Growth factor content in PRP and their applicability in medicine. J Biol Regul Homeost Agents 2012;26(2, suppl 1) :3S-22S

24 Khan BT, Kiani MN, Saeed MHB, et al. Risk factors assessment for dry sockets: A logistic regression analysis study. J Oral Maxillofac Surg Med Pathol 2015;27:753-756

25 Rakhshan V. Common risk factors of dry socket (alveolitis osteitis) following dental extraction: a brief narrative review. J Stomatol Oral Maxillofac Surg 2018;119(5):407-411

26 Fortunato L, Bennardo F, Buffone C, Giudice A. Is the application of platelet concentrates effective in the prevention and treatment of medication-related osteonecrosis of the jaw? A systematic review. J Craniomaxillofac Surg 2020;48(3):268-285

27 Kreisler M, Christoffers AB, Al-Haj H, Willershausen B, d'Hoedt B. Low level 809-nm diode laser-induced in vitro stimulation of the proliferation of human gingival fibroblasts. Lasers Surg Med 2002;30(5):365-369

28 Basso FG, Pansani TN, Turrioni AP, Bagnato VS, Hebling J, de Souza Costa CA. In vitro wound healing improvement by low-level laser therapy application in cultured gingival fibroblasts. Int J Dent 2012;2012:719452

29 Saygun I, Karacay S, Serdar M, Ural AU, Sencimen M, Kurtis B. Effects of laser irradiation on the release of basic fibroblast growth factor (bFGF), insulin like growth factor-1 (IGF-1), and receptor of IGF-1 (IGFBP3) from gingival fibroblasts. Lasers Med Sci 2008;23(2):211-215

30 Posten W, Wrone DA, Dover JS, Arndt KA, Silapunt S, Alam M. Low-level laser therapy for wound healing: mechanism and efficacy. Dermatol Surg 2005;31(3):334-340

31 Peplow PV, Chung T-Y, Baxter GD. Laser photobiomodulation of proliferation of cells in culture: a review of human and animal studies. Photomed Laser Surg 2010;28(Suppl 1) :S3-S40

32 van Roeyen CR, Ostendorf T, Floege J. The platelet-derived growth factor system in renal disease: an emerging role of endogenous inhibitors. Eur J Cell Biol 2012;91(6-7):542-551

33 Chanprapaph K, Vachiramon V, Rattanakaemakorn P. Epidermal growth factor receptor inhibitors: a review of cutaneous adverse events and management. Dermatol Res Pract 2014;2014:734249. Doi: 10.1155/2014/734249 